\title{
Multidisciplinary clinical approach to the management of head and neck cancer
}

\author{
Patrick J. Bradley
}

Received: 9 August 2012/Accepted: 19 September 2012/Published online: 16 October 2012

(C) Springer-Verlag Berlin Heidelberg 2012

Within the practice of cancer care over the past two decades, there has been a continual and rapidly expanding range of potentially efficacious treatment options, which introduce therapeutic dilemmas about optimum management plans and how these should be presented to patients [1]. This increased specialisation and complexity of knowledge has led to the introduction of multidisciplinary teams (MDTs) for the management of patients with cancer [2]. In the past, treatment for all but a few patients with cancer was based on decisions that were made unilaterally, without necessarily following an evidence-based approach [3]. One of the aims of cancer management by a multidisciplinary team hopes to ensure that all patients will benefit from the wisdom of a variety of specialist team members who can share their expertise, professional perspective, and knowledge [1, 3, 4] and has become the model of care in many countries [5]. The introduction of MDTs in England was given impetus by the production of tumour-specific guidance (Improved Outcomes Guidance; IOG), which aimed to standardise and improve the outcomes of cancer care [6]. The benefits of MDT working are thought to include improved communication, coordination, and decision-making between health care team members when weighing up treatment options. Indeed, multidisciplinary discussion can help health care professionals to tailor holistic treatment plans to patients' tumour types, biological markers as well as their comorbidities and social circumstances [7]. Evidence has been provided that multidisciplinary team-working can make a positive impact on

\section{P. J. Bradley $(\square)$}

Emeritus Consultant ORL-HNS, Nottingham University

Hospitals, Queens Medical Centre Campus,

Nottingham NG7 2UH, UK

e-mail: pjbradley@zoo.co.uk the quality of clinical decision-making, clinical outcomes for patients, patients' experience of care and also the impact on the working lives of team members [8].

The introduction of MDT practice for cancer management was originally introduced to counter apparent shortfalls in cancer care provision in the UK in the mid-1990s and aimed to ensure all patients achieved prompt access to expert advice, up-to-date treatments, provided by relevant professionals with specialist knowledge and skills [6]. An additional aspiration was to ensure seamless specialist continuity of care for all patients, as well as the offer of adequate information and support. There is almost universal approval for this strategy [9], which indeed some considers crucial [10], despite the fact that there is little evidence of its effectiveness in improving outcomes [11]. A large survey [5] of MDT members in the UK in 2009, and included 109 from the Head and Neck Service, enabled a set of recommendations to be formulated to define how an effective MDT would work (http://www.ncat.nhs.uk). In summary, the analysis of the survey reveals a strong consensus between MDT members from different tumour types, while also identifying areas that require a more tailored approach, such as the clinical decision-making process, and preparation for and organisation of MDT meetings [5]. In addition, in a systematic review on factors that affect the quality of clinical decision-making of MDTs, several factors have been identified: inclusion of time to prepare for MDTs into team-members' job plans, making teams and leadership skills training available to team-members, and systematic input from nursing personnel would address some of the current shortcomings $[7,12]$.

The management of patients with head and neck cancer is considered complex and requires a multifaceted treatment strategies for a heterogeneous group of tumours 
located in key anatomical, physiological and functionalsites, not only for diagnosis but also for immediate and long-term rehabilitation [13-18]. Case presentation at $\mathrm{HnN}$ MDT affects and changes the clinical staging and therefore improves outcomes in a significant number of patients and improves quality of survival [19-21]. Because head and neck cancer is rare and complex, it has been suggested that advanced stage disease surgery should only be performed in high volume hospitals which will result in a shorter hospital stay, a better long-term survival and cure-rate [2224]. Therefore, the team members involved in such a carepathway are numerous and each has a unique part to play in the each patient's treatment decision-making and subsequent management. The IOG for head and neck cancer in England and Wales [6] has defined the membership of the core team who must attend weekly meetings and sessional commitments should be formally agreed in their job planning process. This team is composed of doctors (surgeons, clinical oncologists, pathologists, radiologists) clinical nurse specialist, speech and language therapist, dietician, nursing staff, MDT coordinator, data manager, team secretary and restorative dentist. The head and neck surgeon is the only job defined and states that "should normally dedicate half of his or her time to head and neck cancer". Also listed is other individuals who because of their designated expertise and should make themselves available whenever their expertise is needed. An audit of the clinical resources available for the care of head and neck cancer patients in England [25] revealed the widespread practice of MDT and the dedication of the specialist care teams. It was identified that there was a lack of non-core member's availability to attend the MDT. Other deficiencies also highlighted involved the provision of supportive services such as imaging and histopathology. The provision of dieticians, and speech and language therapists was patchy and often dependent on local facilities, priorities and workload. A recent updated audit [26] has revealed that there remains a need for increased resources and further changes in practice are required to implement current NHS Cancer Policy and teams need to improve recording of their decision-making, discuss morbidity and mortality and support recruitment to clinical studies. Short and long-term identification and structure rehabilitation is key to the rehabilitation of the treated head and neck patient, and involves an active weekly review of treatment strategies to ensure adequate weight gain, nutrition, voice and swallowing, as well as help to achieve cessation of smoking and dependency on alcohol [27-31]. The MDT environment is an ideal environment to collect, collate and review each patient's progress with patient's availability to complete quality-of-life questionnaire [32].

One area of importance in MDT working is adherence to clinical management guidelines [33-37]. However, the development of clinical management guidelines does not ensure physician adherence, many barriers exist and develop which may need to be identified and targeted solution need to be invented to overcome clinician resistance [38]. Within Europe, some countries, not all, have developed management guidelines for head and neck cancer but most are written in their native language and circulated within each country, thus making comparisons difficult [39-41]. A report [42] has reviewed the pretreatment of head and neck cancer patients to a USA tertiary care centre with recurrent or persistent disease have been treated with significant deviation from NCC guidelines. In 1999, The Netherlands clinical practice guidelines for the management of laryngeal cancer was introduced and a retrospective review reported that their introduction had contributed to uniformity [43], and a follow-up paper [44] continued to report that the efficiency of the care process improved. Another retrospective report from The Netherlands [45] on the management of tongue and floor of mouth squamous cell carcinoma reported that protocol violation occurred in $45 \%$ of patients, this did not result in a worse tumour recurrence, and neither did over-treatment nor under-treatment appeared to affect the overall tumour recurrence.

A solution suggested [46] is a need for stabilising the process of decision-making, and responsibility should be clearly identified for every person who is contributing to the multidisciplinary decision, with a common agreement that serves as a guideline for governing subsequent discussions about clinical interventions in complex cases. They also suggest that responsibility for success and failures should be traced and associated with every member contributing to the decision by constant feedback on whether the endpoints were accomplished or not. The chairman of the MDT should be aware of the outcomes from every situation, keeping in mind that success is not to be taken for granted.

Another area of MDT practice highlighted is the unwarranted practice variation between MDTs and even within MDTs [47]. Evidence of practice variation has been documented in the recent publications of DAHNO6 and DAHNO7 with respect to the management of oropharyngeal cancers and early laryngeal cancers [48, 49]. Ultimately, clinical outcome should be included when assessing MDT performance, but short-term outcome and potentially process measures (such as time from first referral to diagnosis, time from diagnosis to the first treatment, and cost reductions) should also be developed. There is evidence that the ability of an MDT to reach a decision on the first-case presentation and ability of MDT decisions to be implemented appear to be useful markers of the performance of the MDT [7]. Moreover, outcomes such as patient's satisfaction and health care professional 
satisfaction are also increasingly seen as important measures of the effectiveness of health care [50, 51]. Patient involvement in decisions about their treatment is widely considered to be crucial to improving outcomes, and many cancer patients wish to play a more active role in their care. The current structure of cancer MDT meetings makes patient participation very difficult to achieve [52].

The aims for improving the quality of head and neck cancer care has been summarised [53]: (a) to increase the safety of health care by avoiding injuries to patients through care intended to help them, (b) to deliver effective services based on scientific knowledge and to avoid services of no proven benefit, (c) to deliver individualised treatment respectful of and responsive to the patient's preferences, needs, and values, (d) to deliver timely care by reducing wait times and harmful delays, (e) to increase efficiency by not wasting equipment, supplies, ideas, and energy, and (f) to deliver care that is equitable and does not vary by personal characteristics, patient sex, ethnicity, geography, and social economic status.

However, the multidisciplinary team structure has enormous potential to harmonise and improve cancer care through improved documentation of imaging and pathology cancer stage and prognosis, the evaluation of available treatments, surgery, radiotherapy, chemotherapy and novel therapies, involvement of team members in audit of outcomes and active participation in clinical research.

\section{References}

1. Fleissig A, Jenkins V, Catt S, Fellowfield L (2006) Multidisciplinary teams in cancer care: are they effective in the UK? Lancet Oncol 7:935-943

2. Department of Health (2000) The NHS Cancer Plan 2000. The NHS Plan and Services, London. www.dh.gov.uk

3. Brown G (2012) Specialist multidisciplinary team working in the treatment of cancer. BMJ 344:e2780

4. Taylor C, Munro AJ, Glynne-Jones R et al (2010) Multidisciplinary team working in cancer: what is the evidence? BMJ 340:c951

5. Lamb BW, Sevdalis N, Taylor C et al (2012) Multidisciplinary team working across different tumour types: analysis of a national survey. Ann Oncol 23:1293-1300

6. National Institute for Clinical Excellence. Guidance on cancer services improving outcomes in head and neck cancers. The manual. London 2004

7. Lamb B, Brown K, Nagpal K et al (2011) Team decision making by cancer care multidisciplinary teams: a systematic review. Ann Surg Oncol 18(8):2116-2125

8. Blazeby JM, Wilson L, Metcalfe C et al (2006) Analysis of clinical decision-making in multi-disciplinary cancer teams. Ann Oncol 17:457-460

9. Thornton S, Dodwell D (2012) Multidisciplinary team working: the emperor without clothes? Brit J Hosp Med 73(4):186-187

10. Day F, Pollock C, Brook C, Albus A (2010) Multidisciplinary cancer teams: crucial for population health. BMJ 340:c2125
11. Fennell ML, Das IP, Clauser S, Petrelli N, Sainer A (2010) The organisation of multidisciplinary care teams: modelling internal and external influences on cancer care quality. J Natl Cancer Inst Monogr 40:72-80

12. Lamb BW, Sedalis N, Arora S et al (2011) Teamwork and team decision-making at multidisciplinary cancer conferences: barriers, facilitators, and opportunities for improvement. World J Surg 35:1970-1976

13. Gibson MK, Forastiere AA (2004) Multidisciplinary approaches in the management of advanced head and neck tumors: state of the art. Curr Opin Oncol 16:220-224

14. Licitra L, Bossi P, Locati LD (2006) A multidisciplinary approach to squamous cell carcinomas of the head and neck: what is new? Curr Opin Oncol 18:253-257

15. Bernier $\mathbf{J}$ (2008) A multidisciplinary approach to squamous cell carcinoma of the head and neck: an update. Curr Opin Oncol 20:249-255

16. Westin T, Stalfors J (2008) Tumour boards/multidisciplinary head and neck cancer meetings: are they of value to patients, treating staff or a political additional drain on healthcare resources? Curr Opin Otolaryngol Head Neck Surg 16:103-107

17. Wong RJ, Shah JP (2010) The role of the head and neck surgeon in contemporary multidiscipline treatment programs for advanced head and neck cancer. Curr Opin Otolaryngol Head Neck Surg 18:79-82

18. Varkey P, Liu Y-T, Tan NC (2010) Multidisciplinary treatment of head and neck cancer. Semin Plast Surg 24(3):331-334

19. Nguyen NP, Vos P, Lee H et al (2008) Impact of tumour board recommendations on treatment outcome for locally advanced head and neck cancer. Oncology 75:186-191

20. Friedland PL, Bozic B, Dewar J et al (2011) Impact of multidisciplinary team management in head and neck cancer patients. Br J Cancer 104:1246-1248

21. Wheless S, McKinney KA, Zanation AM (2010) A prospective study of the clinical impact of a multidisciplinary head and neck tumour board. Otolaryngol Head Neck Surg 143:650-654

22. Cheung MC, Koniaris LG, Perez E et al (2009) Impact of hospital volume on surgical outcome for head and neck cancer. Ann Surg Oncol 16:1001-1009

23. Gourin CG, Forastiere AA, Sanguineti G et al (2011) Impact of surgeon and hospital volume on short-term outcomes and cost of laryngeal cancer surgical care. Laryngoscope 121:85-90

24. Gourin CG, Forastiere AA, Sanguineti G (2011) Impact of surgeon and hospital care on short-term outcomes and cost of oropharyngeal cancer surgical care. Laryngoscope 121:746-752

25. Bradley PJ, Zutshi B, Nutting CM (2005) An audit of clinical resources available for the care of head and neck cancer patients in England. Clin Oncol 17:604-609

26. Hughes C, Homer J, Bradley PJ et al (2012) An evaluation of current services available for people diagnosed with head and neck cancer in the UK (2009-2010). Clin Oncol [Epub ahead of print]

27. Machin J, Shaw C (1998) A multidisciplinary approach to head and neck cancer. Eur J Cancer Care 7:93-96

28. Dingman C, Hegedus PD, Likes C et al (2008) A coordinated, multidisciplinary approach to caring for the patient with head and neck cancer. J Support Oncol 6(3):125-131

29. Oates J, Clarke JR, Read J et al (2008) Integration of prospective quality of life and nutritional assessment as routine components of multidisciplinary care of patients with head and neck cancer. ANZ J Surg 78(1-2):34-41

30. Gill SS, Frew J, Fry A et al (2011) Priorities for the head and neck cancer patient, their companion and members of the multidisciplinary team and decision regret. Clin Oncol 23(8): $518-524$

31. Starmer H, Sanguineti G, Marur S, Gourin CG (2011) Multidisciplinary head and neck cancer clinic and adherence with speech pathology. Laryngoscope 121(10):2131-2135 
32. Morton R. Toward comprehensive multidisciplinary care for head and neck cancer patients: quality of life vs. survival. Otolaryngol Head Neck Surg 2012; June 11 [Epub ahead of print]

33. Pfister DG, Ang K-K, Brizel DM et al (2011) National Comprehensive Cancer Network (NCCN) Clinical practice guidelines in oncology for head and neck cancers. JNCCN - Journal of the National Comprehensive Cancer. Network 9(6):596-650

34. Roland N, Paleri V (eds) (2011) Head and neck cancer: multidisciplinary management guidelines, 4 th edn. British Association of Otorhinolaryngology Head and Neck Surgery, London. http://www.entuk.org

35. Scottish Intercollegiate Guidelines Network (SIGN) (2006) Diagnosis and Management of Head and Neck Cancer, vol 90. www.sign.ac.uk

36. Gregoire V, Lefebvre J-L, Licitra L, Felip E (2010) Squamous cell carcinoma of the head and neck: EHNS-ESMO-ESTRO clinical recommendations for diagnosis, treatment and follow-up. Ann Oncol 21(Supp 5):v180-v182

37. Chan ATC, Gregoire V, Lefebvre J-L, Licitra L, Felip E (2010) Nasopharyngeal cancer: EHNS-ESMO-ESTRO clinical practice guidelines for diagnosis, treatment and follow-up. Ann Oncol 21(Supp 5):v187-v189

38. Cabana MD, Rand CS, Powe NR et al (1999) Why don't physicians follow clinical practice guidelines? JAMA 282(15): $1458-1465$

39. Knegt PP, Keus RB, Roodenburg JL (2006) The practice guideline "Carcinoma of the oral cavity and oropharynx". Ned Tijdschr Geneeskd 150(2):83-88 (In Dutch)

40. Pastor B, Mesia NR, Cruz HJJ, Isla CD (2010) SEOM clinical guidelines for the treatment of head and neck cancer. Clin Transl Oncol 12(11):3-37 (In Spanish)

41. Toustrup K, Lambertsen K (2010) Ulhoi BP et al. Accelerated diagnosis and treatment iniation for head and neck cancer patients. Ugeskr Laeger 172(4):279-284 (In Danish)

42. Lewis CM, Hessel AC, Roberts DB et al (2010) Pre-referral head and neck cancer treatment. Arch Otolaryngol Head Neck Surg 136(12):1205-1211
43. van Agthoven M, Heule-Dieleman HA, de Boer MF et al (2005) Evaluating adherence to the Dutch guideline for diagnosis, treatment and follow-up of laryngeal carcinomas. Radiother Oncol 74(3):337-344

44. van Agthoven M, Heule-Dieleman HA, Knegt PP et al (2006) Compliance and efficiency before and after implementation of a clinical practice guideline for laryngeal cancinomas. Eur Arch Otorhinolaryngol 263(8):729-737

45. Aarts MC, Hogen Esch TT, Terhaard CH et al (2005). Guidelines in head and neck oncology compliance and consequences of deviations from the standard protocol for tongue and floor of mouth squamous carcinoma. Clin Otolaryngol 30(5):444-450

46. Mazzaferro V, Majno P (2011) Principles for best multidisciplinary meetings. Lancet Oncology 12:323-325

47. Patkar V, Acosta D, Davidson T et al (2012) Using computerised decision support to improve compliance of cancer multidisciplinary meetings with evidence-based guidance. BMJ Open 2:e000439

48. (2010) National head and neck cancer audit data for head and neck oncology 2009-2010 (DAHNO6). The Information Centre. www.ic.nhs.uk, www.DAHNO.com

49. (2011) National head and neck cancer audit data for head and neck oncology 2010-2011 (DAHNO7). The Information Centre. www.ic.nhs.uk, www.DAHNO.com

50. Taylor C, Ramirez AJ (2010) Can we reduce burnout amongst cancer health professionals? Eur J Cancer 46(15):2668-2670

51. Humphries G (2008) The missing member of the head and neck multidisciplinary team: the psychologist. Why we need them. Curr Opin Otolaryngol Head Neck Surg. 16:108-112

52. 2010 National Survey Report (2010) National cancer patients experience survey programme. Department of Health, London. www.dh.gov.uk

53. Weber RS (2007) Improving the quality of head and neck cancer care. Arch Otolaryngol Head Neck Surg 133(12):1188-1192 